\title{
Existence and Ulam stability for implicit fractional q-difference equations
}

\author{
Saïd Abbas ${ }^{1}$, Mouffak Benchohra ${ }^{2,3}$, Nadjet Laledj ${ }^{2}$ and Yong Zhou ${ }^{4,5 *}$ (D
}

\author{
"Correspondence: \\ yzhou@xtu.edu.cn \\ ${ }^{4}$ Faculty of Information Technology, \\ Macau University of Science and \\ Technology, Macau, China \\ ${ }^{5}$ Faculty of Mathematics and \\ Computational Science, Xiangtan \\ University, Hunan, China \\ Full list of author information is \\ available at the end of the article
}

\begin{abstract}
This paper deals with some existence, uniqueness and Ulam-Hyers-Rassias stability results for a class of implicit fractional q-difference equations. Some applications are made of some fixed point theorems in Banach spaces for the existence and uniqueness of solutions, next we prove that our problem is generalized Ulam-Hyers-Rassias stable. Two illustrative examples are given in the last section.
\end{abstract}

MSC: 26A33

Keywords: Fractional q-difference equation; Implicit; Ulam-Hyers-Rassias stability; Fixed point

\section{Introduction}

Fractional differential equations have recently been applied in various areas of engineering, mathematics, physics, and other applied sciences [33]. For some fundamental results in the theory of fractional calculus and fractional differential equations we refer the reader to the monographs $[4-6,23,32,39]$, the papers $[24,34,36-38,40]$ and the references therein. Recently, considerable attention has been given to the existence of solutions of initial and boundary value problems for fractional differential equations and inclusions with Caputo fractional derivative; $[5,22]$. Implicit fractional differential equations were analyzed by many authors; see for instance $[4,5,11-13]$ and the references therein.

Considerable attention has been given to the study of the Ulam stability of functional differential and integral equations; see the monographs $[6,19]$, the papers $[1-3,20,28,30$, $31]$ and the references therein.

Fractional q-difference equations were initiated in the beginning of the 19th century $[7,15]$, and received significant attention in recent years. Some interesting results about initial and boundary value problems of q-difference and fractional q-difference equations can be found in $[9,10,16,17]$ and the references therein. An implicit fractional q-integral equation is considered in [18].

In this paper we discuss the existence, uniqueness and Ulam-Hyers-Rassias stability of solutions for the following implicit fractional q-difference equation:

$$
\left({ }^{c} D_{q}^{\alpha} u\right)(t)=f\left(t, u(t),\left({ }^{c} D_{q}^{\alpha} u\right)(t)\right), \quad t \in I:=[0, T],
$$

(c) The Author(s) 2019. This article is distributed under the terms of the Creative Commons Attribution 4.0 International License (http://creativecommons.org/licenses/by/4.0/), which permits unrestricted use, distribution, and reproduction in any medium, provided you give appropriate credit to the original author(s) and the source, provide a link to the Creative Commons license, and indicate if changes were made. 
with the initial condition

$$
u(0)=u_{0},
$$

where $q \in(0,1), \alpha \in(0,1], T>0, f: I \times \mathbb{R} \times \mathbb{R} \rightarrow \mathbb{R}$ is a given continuous function, and ${ }^{c} D_{q}^{\alpha}$ is the Caputo fractional q-difference derivative of order $\alpha$.

This paper initiates the study of implicit Caputo fractional q-difference equations.

\section{Preliminaries}

Consider the complete metric space $C(I):=C(I, \mathbb{R})$ of continuous functions from $I$ into $\mathbb{R}$ equipped with the usual metric

$$
d(u, v):=\max _{t \in I}|u(t)-v(t)|
$$

Notice that $C(I)$ is a Banach space with the supremum (uniform) norm

$$
\|u\|_{\infty}:=\sup _{t \in I}|u(t)|
$$

As usual, $L^{1}(I)$ denotes the space of measurable functions $v: I \rightarrow \mathbb{R}$ which are Lebesgue integrable with the norm

$$
\|v\|_{1}=\int_{I}|v(t)| d t
$$

Let us recall some definitions and properties of fractional q-calculus. For $a \in \mathbb{R}$, we set

$$
[a]_{q}=\frac{1-q^{a}}{1-q} .
$$

The q analogue of the power $(a-b)^{n}$ is

$$
(a-b)^{(0)}=1, \quad(a-b)^{(n)}=\prod_{k=0}^{n-1}\left(a-b q^{k}\right) ; \quad a, b \in \mathbb{R}, n \in \mathbb{N} .
$$

In general,

$$
(a-b)^{(\alpha)}=a^{\alpha} \prod_{k=0}^{\infty}\left(\frac{a-b q^{k}}{a-b q^{k+\alpha}}\right) ; \quad a, b, \alpha \in \mathbb{R} .
$$

Definition 2.1 ([21]) The q-gamma function is defined by

$$
\Gamma_{q}(\xi)=\frac{(1-q)^{(\xi-1)}}{(1-q)^{\xi-1}} ; \quad \xi \in \mathbb{R}-\{0,-1,-2, \ldots\}
$$

Notice that the q-gamma function satisfies $\Gamma_{q}(1+\xi)=[\xi]_{q} \Gamma_{q}(\xi)$. 
Definition 2.2 ([21]) The q-derivative of order $n \in \mathbb{N}$ of a function $u: I \rightarrow \mathbb{R}$ is defined by $\left(D_{q}^{0} u\right)(t)=u(t)$,

$$
\left(D_{q} u\right)(t):=\left(D_{q}^{1} u\right)(t)=\frac{u(t)-u(q t)}{(1-q) t} ; \quad t \neq 0, \quad\left(D_{q} u\right)(0)=\lim _{t \rightarrow 0}\left(D_{q} u\right)(t),
$$

and

$$
\left(D_{q}^{n} u\right)(t)=\left(D_{q} D_{q}^{n-1} u\right)(t) ; \quad t \in I, n \in\{1,2, \ldots\}
$$

Set $I_{t}:=\left\{t q^{n}: n \in \mathbb{N}\right\} \cup\{0\}$.

Definition 2.3 ([21]) The q-integral of a function $u: I_{t} \rightarrow \mathbb{R}$ is defined by

$$
\left(I_{q} u\right)(t)=\int_{0}^{t} u(s) d_{q} s=\sum_{n=0}^{\infty} t(1-q) q^{n} f\left(t q^{n}\right)
$$

provided that the series converges.

We note that $\left(D_{q} I_{q} u\right)(t)=u(t)$, while if $u$ is continuous at 0 , then

$$
\left(I_{q} D_{q} u\right)(t)=u(t)-u(0) .
$$

Definition 2.4 ([8]) The Riemann-Liouville fractional q-integral of order $\alpha \in \mathbb{R}_{+}:=$ $[0, \infty)$ of a function $u: I \rightarrow \mathbb{R}$ is defined by $\left(I_{q}^{0} u\right)(t)=u(t)$, and

$$
\left(I_{q}^{\alpha} u\right)(t)=\int_{0}^{t} \frac{(t-q s)^{(\alpha-1)}}{\Gamma_{q}(\alpha)} u(s) d_{q} s ; \quad t \in I
$$

Lemma $2.5([26])$ For $\alpha \in \mathbb{R}_{+}:=[0, \infty)$ and $\lambda \in(-1, \infty)$ we have

$$
\left(I_{q}^{\alpha}(t-a)^{(\lambda)}\right)(t)=\frac{\Gamma_{q}(1+\lambda)}{\Gamma(1+\lambda+\alpha)}(t-a)^{(\lambda+\alpha)} ; \quad 0<a<t<T .
$$

In particular,

$$
\left(I_{q}^{\alpha} 1\right)(t)=\frac{1}{\Gamma_{q}(1+\alpha)} t^{(\alpha)}
$$

Definition 2.6 ([27]) The Riemann-Liouville fractional q-derivative of order $\alpha \in \mathbb{R}_{+}$of a function $u: I \rightarrow \mathbb{R}$ is defined by $\left(D_{q}^{0} u\right)(t)=u(t)$, and

$$
\left(D_{q}^{\alpha} u\right)(t)=\left(D_{q}^{[\alpha]} I_{q}^{[\alpha]-\alpha} u\right)(t) ; \quad t \in I
$$

where $[\alpha]$ is the integer part of $\alpha$.

Definition 2.7 ([27]) The Caputo fractional q-derivative of order $\alpha \in \mathbb{R}_{+}$of a function $u: I \rightarrow \mathbb{R}$ is defined by $\left({ }^{C} D_{q}^{0} u\right)(t)=u(t)$, and

$$
\left({ }^{C} D_{q}^{\alpha} u\right)(t)=\left(I_{q}^{[\alpha]-\alpha} D_{q}^{[\alpha]} u\right)(t) ; \quad t \in I .
$$


Lemma 2.8 ([27]) Let $\alpha \in \mathbb{R}_{+}$. Then the following equality holds:

$$
\left(I_{q}^{\alpha C} D_{q}^{\alpha} u\right)(t)=u(t)-\sum_{k=0}^{[\alpha]-1} \frac{t^{k}}{\Gamma_{q}(1+k)}\left(D_{q}^{k} u\right)(0) .
$$

In particular, if $\alpha \in(0,1)$, then

$$
\left(I_{q}^{\alpha C} D_{q}^{\alpha} u\right)(t)=u(t)-u(0)
$$

From the above lemma, and in order to define the solution for the problem (1)-(2), we need the following lemma.

Lemma 2.9 Let $f: I \times \mathbb{R} \times \mathbb{R} \rightarrow \mathbb{R}$ such that $f(\cdot, u, v) \in C(I)$, for each $u, v \in \mathbb{R}$. Then the problem (1)-(2) is equivalent to the problem of obtaining the solutions of the integral equation

$$
g(t)=f\left(t, u_{0}+\left(I_{q}^{\alpha} g\right)(t), g(t)\right),
$$

and if $g(\cdot) \in C(I)$, is the solution of this equation, then

$$
u(t)=u_{0}+\left(I_{q}^{\alpha} g\right)(t)
$$

Proof Let $u$ be a solution of problem (1)-(2), and let $g(t)=\left({ }^{C} D_{q}^{\alpha} u\right)(t)$; for $t \in I$. We will prove that $u(t)=u_{0}+\left(I_{q}^{\alpha} g\right)(t)$, and $g$ satisfies Eq. (3). From Lemma 2.8, we have $u(t)=$ $u_{0}+\left(I_{q}^{\alpha} g\right)(t)$, and it is easy to see that Eq. (1) implies (3). Reciprocally, if $u$ satisfies the integral equation $u(t)=u_{0}+\left(I_{q}^{\alpha} g\right)(t)$, and if $g$ satisfies Eq. (3), then $u$ is a solution of the problem (1)-(2).

Now, we consider the Ulam stability for the problem (1)-(2). Let $\epsilon>0$ and $\Phi: I \rightarrow \mathbb{R}_{+}$ be a continuous function. We consider the following inequalities:

$$
\begin{aligned}
& \left|\left({ }^{c} D_{q}^{\alpha} u\right)(t)-f\left(t, u(t),\left({ }^{c} D_{q}^{\alpha} u\right)(t)\right)\right| \leq \epsilon ; \quad t \in I, \\
& \left|\left({ }^{c} D_{q}^{\alpha} u\right)(t)-f\left(t, u(t),\left({ }^{c} D_{q}^{\alpha} u\right)(t)\right)\right| \leq \Phi(t) ; \quad t \in I, \\
& \left|\left({ }^{c} D_{q}^{\alpha} u\right)(t)-f\left(t, u(t),\left({ }^{c} D_{q}^{\alpha} u\right)(t)\right)\right| \leq \epsilon \Phi(t) ; \quad t \in I .
\end{aligned}
$$

Definition 2.10 ([5, 30]) The problem (1)-(2) is Ulam-Hyers stable if there exists a real number $c_{f}>0$ such that for each $\epsilon>0$ and for each solution $u \in C(I)$ of the inequality (4) there exists a solution $v \in C(I)$ of (1)-(2) with

$$
|u(t)-v(t)| \leq \epsilon c_{f} ; \quad t \in I
$$

Definition 2.11 $([5,30])$ The problem (1)-(2) is generalized Ulam-Hyers stable if there exists $c_{f}: C\left(\mathbb{R}_{+}, \mathbb{R}_{+}\right)$with $c_{f}(0)=0$ such that for each $\epsilon>0$ and for each solution $u \in C(I)$ of the inequality (4) there exists a solution $v \in C(I)$ of (1)-(2) with

$$
|u(t)-v(t)| \leq c_{f}(\epsilon) ; \quad t \in I .
$$


Definition 2.12 ([5, 30]) The problem (1)-(2) is Ulam-Hyers-Rassias stable with respect to $\Phi$ if there exists a real number $c_{f, \Phi}>0$ such that for each $\epsilon>0$ and for each solution $u \in C(I)$ of the inequality (6) there exists a solution $v \in C(I)$ of (1)-(2) with

$$
|u(t)-v(t)| \leq \epsilon c_{f, \Phi} \Phi(t) ; \quad t \in I .
$$

Definition 2.13 ([5, 30]) The problem (1) is generalized Ulam-Hyers-Rassias stable with respect to $\Phi$ if there exists a real number $c_{f, \Phi}>0$ such that for each solution $u \in C_{\gamma, \ln }$ of the inequality (5) there exists a solution $v \in C_{\gamma, \ln }$ of (1)-(2) with

$$
|u(t)-v(t)| \leq c_{f, \Phi} \Phi(t) ; \quad t \in I \text {. }
$$

Remark 2.14 It is clear that

(i) Definition $2.10 \Rightarrow$ Definition 2.11,

(ii) Definition $2.12 \Rightarrow$ Definition 2.13,

(iii) Definition 2.12 for $\Phi(\cdot)=1 \Rightarrow$ Definition 2.10

One can have similar remarks for the inequalities (4) and (6).

Definition 2.15 ([29]) A nondecreasing function $\phi: \mathbb{R}_{+} \rightarrow \mathbb{R}_{+}$is called a comparison function if it satisfies one of the following conditions:

(1) For any $t>0$ we have

$$
\lim _{n \rightarrow \infty} \phi^{(n)}(t)=0,
$$

where $\phi^{(n)}$ denotes the $n$th iteration of $\phi$.

(2) The function $\phi$ is right-continuous and satisfies

$$
\phi(t)<t \quad \forall t>0 .
$$

Remark 2.16 The choice $\phi(t)=k t$ with $0<k<1$ gives the classical Banach contraction mapping principle.

For our purpose we will need the following fixed point theorems.

Theorem $2.17([14,25])$ Let $(X, d)$ be a complete metric space and $T: X \rightarrow X$ be a mapping such that

$$
d(T(x), T(y)) \leq \phi(d(x, y)),
$$

where $\phi$ is a comparison function. Then $T$ has a unique fixed point in $X$.

Theorem 2.18 (Schauder fixed point theorem [35]) Let $X$ be a Banach space, $D$ be a bounded closed convex subset of $X$ and $T: D \rightarrow D$ be a compact and continuous map. Then $T$ has at least one fixed point in $D$. 


\section{Existence results}

In this section, we are concerned with the existence and uniqueness of solutions of the problem (1)-(2).

Definition 3.1 By a solution of the problem (1)-(2) we mean a continuous function $u \in$ $C(I)$ that satisfies Eq. (1) on $I$ and the initial condition (2).

The following hypotheses will be used in the sequel.

$\left(H_{1}\right)$ The function $f$ satisfies the generalized Lipschitz condition:

$$
\left|f\left(t, u_{1}, v_{1}\right)-f\left(t, u_{2}, v_{2}\right)\right| \leq \phi_{1}\left(\left|u_{1}-u_{2}\right|\right)+\phi_{2}\left(\left|v_{1}-v_{2}\right|\right)
$$

for $t \in I$ and $u_{1}, u_{2}, v_{1}, v_{2} \in \mathbb{R}$, where $\phi_{1}$ and $\phi_{2}$ are comparison functions.

$\left(H_{2}\right)$ There exist functions $p, d, r \in C(I,[0, \infty))$ with $r(t)<1$ such that

$$
|f(t, u, v)| \leq p(t)+d(t)|u|+r(t)|v|, \quad \text { for each } t \in I \text { and } u, v \in \mathbb{R}
$$

Set

$$
p^{*}=\sup _{t \in I} p(t), \quad d^{*}=\sup _{t \in I} d(t), \quad r^{*}=\sup _{t \in I} r(t)
$$

First, we prove an existence and uniqueness result for the problem (1)-(2).

Theorem 3.2 Assume that the hypothesis $\left(H_{1}\right)$ holds. Then there exists a unique solution of problem (1)-(2) on I.

Proof By using Lemma 2.9, we transform the problem (1)-(2) into a fixed point problem. Consider the operator $N: C(I) \rightarrow C(I)$ defined by

$$
(N u)(t)=u_{0}+\left(I_{q}^{\alpha} g\right)(t) ; \quad t \in I,
$$

where $g \in C(I)$ such that

$$
g(t)=f(t, u(t), g(t)), \quad \text { or } \quad g(t)=f\left(t, u_{0}+\left(I_{q}^{\alpha} g\right)(t), g(t)\right) \text {. }
$$

Let $u, v \in C(I)$. Then, for $t \in I$, we have

$$
|(N u)(t)-(N v)(t)| \leq \int_{0}^{t} \frac{(t-q s)^{(\alpha-1)}}{\Gamma_{q}(\alpha)}|g(s)-h(s)| d_{q} s,
$$

where $g, h \in C(I)$ such that

$$
g(t)=f(t, u(t), g(t))
$$

and

$$
h(t)=f(t, v(t), h(t)) .
$$


From $\left(H_{1}\right)$, we obtain

$$
|g(t)-h(t)| \leq \phi_{1}(|u(t)-v(t)|)+\phi_{2}(|g(t)-h(t)|) .
$$

Thus

$$
|g(t)-h(t)| \leq\left(I d-\phi_{2}\right)^{-1} \phi_{1}(|u(t)-v(t)|),
$$

where $I d$ is the identity function.

Set

$$
L:=\sup _{t \in I} \int_{0}^{T} \frac{(t-q s)^{(\alpha-1)}}{\Gamma_{q}(\alpha)} d_{q} s,
$$

and $\phi:=L\left(I d-\phi_{2}\right)^{-1} \phi_{1}$. From (8), we get

$$
\begin{aligned}
|(N u)(t)-(N v)(t)| & \leq \phi(|u(t)-v(t)|) \\
& \leq \phi(d(u, v))
\end{aligned}
$$

Hence, we get

$$
d(N(u), N(v)) \leq \phi(d(u, v))
$$

Consequently, from Theorem 2.17, the operator $N$ has a unique fixed point, which is the unique solution of the problem (1)-(2).

Theorem 3.3 Assume that the hypothesis $\left(\mathrm{H}_{2}\right)$ holds. If

$$
r^{*}+L d^{*}<1
$$

then the problem (1)-(2) has at least one solution defined on I.

Proof Let $N$ be the operator defined in (7). Set

$$
R \geq \frac{L p^{*}}{1-r^{*}-L d^{*}}
$$

and consider the closed and convex ball $B_{R}=\left\{u \in C(I):\|u\|_{\infty} \leq R\right\}$.

Let $u \in B_{R}$. Then, for each $t \in I$, we have

$$
|(N u)(t)| \leq \int_{0}^{t} \frac{(t-q s)^{(\alpha-1)}}{\Gamma_{q}(\alpha)}|g(s)| d_{q} s
$$

where $g \in C(I)$ such that

$$
g(t)=f(t, u(t), g(t))
$$


By using $\left(H_{2}\right)$, for each $t \in I$ we have

$$
\begin{aligned}
|g(t)| & \leq p(t)+d(t)|u(t)|+r(t)|g(t)| \\
& \leq p^{*}+d^{*}\|u\|_{\infty}+r^{*}|g(t)| \\
& \leq p^{*}+d^{*} R+r^{*}|g(t)| .
\end{aligned}
$$

Thus

$$
|g(t)| \leq \frac{p^{*}+d^{*} R}{1-r^{*}}
$$

Hence

$$
\|N(u)\|_{\infty} \leq \frac{L\left(p^{*}+d^{*} R\right)}{1-r^{*}}
$$

which implies that

$$
\|N(u)\|_{\infty} \leq R
$$

This proves that $N$ maps the ball $B_{R}$ into $B_{R}$. We shall show that the operator $N: B_{R} \rightarrow B_{R}$ is continuous and compact. The proof will be given in three steps.

Step 1: $N$ is continuous.

Let $\left\{u_{n}\right\}_{n \in \mathbb{N}}$ be a sequence such that $u_{n} \rightarrow u$ in $B_{R}$. Then, for each $t \in I$, we have

$$
\left|\left(N u_{n}\right)(t)-(N u)(t)\right| \leq \int_{0}^{t} \frac{(t-q s)^{(\alpha-1)}}{\Gamma_{q}(\alpha)}\left|\left(g_{n}(s)-g(s)\right)\right| d_{q} s,
$$

where $g_{n}, g \in C(I)$ such that

$$
g_{n}(t)=f\left(t, u_{n}(t), g_{n}(t)\right)
$$

and

$$
g(t)=f(t, u(t), g(t))
$$

Since $u_{n} \rightarrow u$ as $n \rightarrow \infty$ and $f$ is continuous function, we get

$$
g_{n}(t) \rightarrow g(t) \quad \text { as } n \rightarrow \infty \text {, for each } t \in I .
$$

Hence

$$
\left\|N\left(u_{n}\right)-N(u)\right\|_{\infty} \leq \frac{p^{*}+d^{*} R}{1-r^{*}}\left\|g_{n}-g\right\|_{\infty} \rightarrow 0 \quad \text { as } n \rightarrow \infty
$$

Step 2: $N\left(B_{R}\right)$ is bounded. This is clear since $N\left(B_{R}\right) \subset B_{R}$ and $B_{R}$ is bounded.

Step 3: $N$ maps bounded sets into equicontinuous sets in $B_{R}$. 
Let $t_{1}, t_{2} \in I$, such that $t_{1}<t_{2}$ and let $u \in B_{R}$. Then, we have

$$
\begin{aligned}
\left|(N u)\left(t_{1}\right)-(N u)\left(t_{2}\right)\right| \leq & \int_{0}^{t_{1}} \frac{\left|\left(t_{2}-q s\right)^{(\alpha-1)}-\left(t_{1}-q s\right)^{(\alpha-1)}\right|}{\Gamma_{q}(\alpha)}|g(s)| d_{q} s \\
& +\int_{t_{1}}^{t_{2}} \frac{\left|\left(t_{2}-q s\right)^{(\alpha-1)}\right|}{\Gamma_{q}(\alpha)}|g(s)| d_{q} s,
\end{aligned}
$$

where $g \in C(I)$ such that $g(t)=f(t, u(t), g(t))$. Hence

$$
\begin{aligned}
\left|(N u)\left(t_{1}\right)-(N u)\left(t_{2}\right)\right| \leq & \frac{p^{*}+d^{*} R}{1-r^{*}} \int_{0}^{t_{1}} \frac{\left|\left(t_{2}-q s\right)^{(\alpha-1)}-\left(t_{1}-q s\right)^{(\alpha-1)}\right|}{\Gamma_{q}(\alpha)} d_{q} s \\
& +\frac{p^{*}+d^{*} R}{1-r^{*}} \int_{t_{1}}^{t_{2}} \frac{\left|\left(t_{2}-q s\right)^{(\alpha-1)}\right|}{\Gamma_{q}(\alpha)} d_{q} s .
\end{aligned}
$$

As $t_{1} \rightarrow t_{2}$ and since $G$ is continuous, the right-hand side of the above inequality tends to zero.

As a consequence of the above three steps with the Arzelá-Ascoli theorem, we can conclude that $N: B_{R} \rightarrow B_{R}$ is continuous and compact.

From an application of Theorem 2.18, we deduce that $N$ has at least a fixed point which is a solution of problem (1)-(2).

\section{Ulam stability results}

In this section, we are concerned with the generalized Ulam-Hyers-Rassias stability results of the problem (1)-(2).

The following hypotheses will be used in the sequel.

$\left(H_{3}\right)$ There exist functions $p_{1}, p_{2}, p_{3} \in C(I,[0, \infty))$ with $p_{3}(t)<1$ such that

$$
\begin{aligned}
& (1+|u|+|v|)|f(t, u, v)| \\
& \quad \leq p_{1}(t) \Phi(t)+p_{2}(t) \Phi(t)|u|+p_{3}(t)|v|, \quad \text { for each } t \in I \text { and } u, v \in \mathbb{R} .
\end{aligned}
$$

$\left(H_{4}\right)$ There exists $\lambda_{\Phi}>0$ such that for each $t \in I$, we have

$$
\left(I_{q}^{\alpha} \Phi\right)(t) \leq \lambda_{\Phi} \Phi(t)
$$

Set $\Phi^{*}=\sup _{t \in I} \Phi(t)$ and

$$
p_{i}^{*}=\sup _{t \in I} p_{i}(t), \quad i \in\{1,2,3\}
$$

Theorem 4.1 Assume that the hypotheses $\left(H_{3}\right)$ and $\left(H_{4}\right)$ hold. If

$$
p_{3}^{*}+L p_{2}^{*} \Phi^{*}<1
$$

then the problem (1)-(2) has at least one solution and it is generalized Ulam-HyersRassias stable.

Proof Consider the operator $N$ defined in (7). We can see that hypothesis $\left(H_{3}\right)$ implies $\left(H_{2}\right)$ with $p \equiv p_{1} \Phi, d \equiv p_{2} \Phi$ and $r \equiv p_{3}$. 
Let $u$ be a solution of the inequality (5), and let us assume that $v$ is a solution of the problem (1)-(2). Thus, we have

$$
v(t)=u_{0}+\left(I_{q}^{\alpha} h\right)(t)
$$

where $h \in C(I)$ such that $h(t)=f(t, v(t), h(t))$.

From the inequality (5) for each $t \in I$, we have

$$
\left|u(t)-u_{0}-\left(I_{q}^{\alpha} g\right)(t)\right| \leq\left(I_{q}^{\alpha} \Phi\right)(t)
$$

where $g \in C(I)$ such that $g(t)=f(t, u(t), g(t))$.

From the hypotheses $\left(H_{3}\right)$ and $\left(H_{4}\right)$, for each $t \in I$, we get

$$
\begin{aligned}
|u(t)-v(t)| & \leq\left|u(t)-u_{0}-\left(I_{q}^{\alpha} g\right)(t)+\left(I_{q}^{\alpha}(g-h)\right)(t)\right| \\
& \leq\left(I_{q}^{\alpha} \Phi\right)(t)+\int_{0}^{t} \frac{(t-q s)^{(\alpha-1)}}{\Gamma_{q}(\alpha)}(|g(s)|+|h(s)|) d_{q} s \\
& \leq\left(I_{q}^{\alpha} \Phi\right)(t)+\frac{p_{1}^{*}+p_{2}^{*}}{1-p_{3}^{*}}\left(I_{q}^{\alpha} \Phi\right)(t) \\
& \leq \lambda_{\phi} \Phi(t)+2 \lambda_{\phi} \frac{p_{1}^{*}+p_{2}^{*}}{1-p_{3}^{*}} \Phi(t) \\
& \leq\left[1+2 \frac{p_{1}^{*}+p_{2}^{*}}{1-p_{3}^{*}}\right] \lambda_{\phi} \Phi(t) \\
& :=c_{f, \Phi} \Phi(t) .
\end{aligned}
$$

Hence, the problem (1)-(2) is generalized Ulam-Hyers-Rassias stable.

\section{Examples}

Example 1 Consider the following problem of implicit fractional $\frac{1}{4}$-difference equations:

$$
\left\{\begin{array}{l}
\left({ }^{c} D_{\frac{1}{4}}^{\frac{1}{2}} u\right)(t)=f\left(t, u(t),\left({ }^{c} D_{\frac{1}{4}}^{\frac{1}{2}} u\right)(t)\right) ; \quad t \in[0,1] \\
u(0)=1
\end{array}\right.
$$

where

$$
f\left(t, u(t),\left({ }^{c} D_{\frac{1}{4}}^{\frac{1}{2}} u\right)(t)\right)=\frac{t^{2}}{1+|u(t)|+\left|{ }^{c} D_{\frac{1}{4}}^{\frac{1}{2}} u(t)\right|}\left(e^{-7}+\frac{1}{e^{t+5}}\right) u(t) ; \quad t \in[0,1] .
$$

The hypothesis $\left(H_{1}\right)$ is satisfied with

$$
\phi_{1}(t)=\phi_{2}(t)=t^{2}\left(e^{-7}+\frac{1}{e^{t+5}}\right) t
$$

Hence, Theorem 3.2 implies that our problem (9) has a unique solution defined on $[0,1]$. 
Example 2 Consider now the following problem of implicit fractional $\frac{1}{4}$-difference equations:

$$
\left\{\begin{array}{l}
\left({ }^{c} D_{\frac{1}{4}}^{\frac{1}{2}} u\right)(t)=f\left(t, u(t),\left({ }^{c} D_{\frac{1}{4}}^{\frac{1}{2}} u\right)(t)\right) ; \quad t \in[0,1], \\
u(0)=2
\end{array}\right.
$$

where

$$
\left\{\begin{array}{l}
f(t, x, y)=\frac{t^{2}}{1+|x|+|y|}\left(e^{-7}+\frac{1}{e^{t+5}}\right)\left(t^{2}+x t^{2}+y\right) ; \quad t \in(0,1], \\
f(0, x, y)=0 .
\end{array}\right.
$$

The hypothesis $\left(H_{3}\right)$ is satisfied with $\Phi(t)=t^{2}$ and $p_{i}(t)=\left(e^{-7}+\frac{1}{e^{t+5}}\right) t ; i \in\{1,2,3\}$. Hence, Theorem 3.3 implies that our problem (10) has at least a solution defined on $[0,1]$.

Also, the hypothesis $\left(H_{4}\right)$ is satisfied. Indeed, for each $t \in(0,1]$, there exists a real number $0<\epsilon<1$ such that $\epsilon<t \leq 1$, and

$$
\begin{aligned}
\left(I_{q}^{\alpha} \Phi\right)(t) & \leq \frac{t^{2}}{\epsilon^{2}\left(1+q+q^{2}\right)} \\
& \leq \frac{1}{\epsilon^{2}} \Phi(t) \\
& =\lambda_{\Phi} \Phi(t) .
\end{aligned}
$$

Consequently, Theorem 4.1 implies that the problem (10) is generalized Ulam-HyersRassias stable.

\section{Funding}

The work was supported by the Fundo para o Desenvolvimento das Ciências e da Tecnologia (FDCT) of Macau under Grant 0074/2019/A2 and the National Natural Science Foundation of China (No. 11671339).

\section{Availability of data and materials}

Not applicable.

\section{Competing interests}

The authors declare that they have no competing interests.

\section{Authors' contributions}

Each of the authors, SA, MB, NL and YZ, contributed equally to each part of this work. All authors read and approved the final manuscript.

\section{Author details}

${ }^{1}$ Department of Mathematics, Tahar Moulay University of Saïda, Saïda, Algeria. ${ }^{2}$ Laboratory of Mathematics, Djillali Liabes University of Sidi Bel-Abbès, Sidi Bel-Abbès, Algeria. ${ }^{3}$ Department of Mathematics, College of Science, King Saud University, Riyadh, Saudi Arabia. ${ }^{4}$ Faculty of Information Technology, Macau University of Science and Technology, Macau, China. ${ }^{5}$ Faculty of Mathematics and Computational Science, Xiangtan University, Hunan, China.

\section{Publisher's Note}

Springer Nature remains neutral with regard to jurisdictional claims in published maps and institutional affiliations.

Received: 20 August 2019 Accepted: 7 November 2019 Published online: 20 November 2019

\section{References}

1. Abbas, S., Albarakati, W., Benchohra, M., N'Guérékata, G.M.: Existence and Ulam stabilities for Hadamard fractional integral equations in Fréchet spaces. J. Fract. Calc. Appl. 7(2), 1-12 (2016)

2. Abbas, S., Albarakati, W.A., Benchohra, M., Henderson, J.: Existence and Ulam stabilities for Hadamard fractional integral equations with random effects. Electron. J. Differ. Equ. 2016, Article ID 25 (2016) 
3. Abbas, S., Albarakati, W.A., Benchohra, M., Sivasundaram, S.: Dynamics and stability of Fredholm type fractional order Hadamard integral equations. Nonlinear Stud. 22(4), 673-686 (2015)

4. Abbas, S., Benchohra, M., Graef, J.R., Henderson, J.: Implicit Fractional Differential and Integral Equations: Existence and Stability. de Gruyter, Berlin (2018)

5. Abbas, S., Benchohra, M., N'Guérékata, G.M.: Topics in Fractional Differential Equations. Springer, New York (2012)

6. Abbas, S., Benchohra, M., N'Guérékata, G.M.: Advanced Fractional Differential and Integral Equations. Nova Publ. (Nova Science Publishers), New York (2015)

7. Adams, C.R.: On the linear ordinary q-difference equation. Ann. Math. 30, 195-205 (1928)

8. Agarwal, R.: Certain fractional q-integrals and q-derivatives. Proc. Camb. Philos. Soc. 66, 365-370 (1969)

9. Ahmad, B.: Boundary value problem for nonlinear third order q-difference equations. Electron. J. Differ. Equ. 2011 Article ID 94 (2011)

10. Ahmad, B., Ntouyas, S.K., Purnaras, L.K.: Existence results for nonlocal boundary value problems of nonlinear fractional q-difference equations. Adv. Differ. Equ. 2012, Article ID 140 (2012)

11. Benchohra, M., Berhoun, F., N'Guérékata, G.M.: Bounded solutions for fractional order differential equations on the half-line. Bull. Math. Anal. Appl. 146(4), 62-71 (2012)

12. Benchohra, M., Bouriah, S., Darwish, M.: Nonlinear boundary value problem for implicit differential equations of fractional order in Banach spaces. Fixed Point Theory 18(2), 457-470 (2017)

13. Benchohra, M., Bouriah, S., Henderson, J.: Existence and stability results for nonlinear implicit neutral fractional differential equations with finite delay and impulses. Commun. Appl. Nonlinear Anal. 22(1), 46-67 (2015)

14. Browder, F.: On the convergence of successive approximations for nonlinear functional equations. Indag. Math. 30 27-35 (1968)

15. Carmichael, R.D.: The general theory of linear q-difference equations. Am. J. Math. 34, 147-168 (1912)

16. El-Shahed, M., Hassan, H.A.: Positive solutions of q-difference equation. Proc. Am. Math. Soc. 138, 1733-1738 (2010)

17. Etemad, S., Ntouyas, S.K., Ahmad, B.: Existence theory for a fractional q-integro-difference equation with q-integral boundary conditions of different orders. Mathematics 7, Article ID 659 (2019)

18. Jleli, M., Mursaleen, M., Samet, B.: Q-integral equations of fractional orders. Electron. J. Differ. Equ. 2016, Article ID 17 (2016)

19. Jung, S.-M.: Hyers-Ulam-Rassias Stability of Functional Equations in Mathematical Analysis. Hadronic Press, Palm Harbor (2001)

20. Jung, S.-M.: Hyers-Ulam-Rassias Stability of Functional Equations in Nonlinear Analysis. Springer, New York (2011)

21. Kac, V., Cheung, P.: Quantum Calculus. Springer, New York (2002)

22. Kilbas, A.A.: Hadamard-type fractional calculus. J. Korean Math. Soc. 38(6), 1191-1204 (2001)

23. Kilbas, A.A., Srivastava, H.M., Trujillo, J.J.: Theory and Applications of Fractional Differential Equations. North-Holland Mathematics Studies, vol. 204. Elsevier, Amsterdam (2006)

24. Li, M., Wang, J.: Finite time stability of fractional delay differential equations. Appl. Math. Lett. 64, 170-176 (2017)

25. Matkowski, J.: Integrable solutions of functional equations. Diss. Math. 127, 1-68 (1975)

26. Rajkovic, P.M., Marinkovic, S.D., Stankovic, M.S.: Fractional integrals and derivatives in q-calculus. Appl. Anal. Discrete Math. 1, 311-323 (2007)

27. Rajkovic, P.M., Marinkovic, S.D., Stankovic, M.S.: On q-analogues of Caputo derivative and Mittag-Leffler function. Fract. Calc. Appl. Anal. 10, 359-373 (2007)

28. Rassias, Th.M.: On the stability of linear mappings in Banach spaces. Proc. Am. Math. Soc. 72, 297-300 (1978)

29. Rus, I., Petrusel, A., Petrusel, G.: Fixed Point Theory. Cluj University Press, Cluj (2008)

30. Rus, I.A.: Ulam stability of ordinary differential equations. Stud. Univ. Babeş-Bolyai, Math. LIV(4), 125-133 (2009)

31. Rus, I.A.: Remarks on Ulam stability of the operatorial equations. Fixed Point Theory 10, 305-320 (2009)

32. Samko, S.G., Kilbas, A.A., Marichev, O.I.: Fractional Integrals and Derivatives. Theory and Applications. Gordon \& Breach, Amsterdam (1987) (English translation from the Russian)

33. Tarasov, V.E.: Fractional Dynamics: Application of Fractional Calculus to Dynamics of Particles, Fields and Media. Springer, Heidelberg; Higher Education Press, Beijing (2010)

34. Tenreiro Machado, J.A., Kiryakova, V.: The chronicles of fractional calculus. Fract. Calc. Appl. Anal. 20, $307-336$ (2017)

35. Toledano, J.M.A., Benavides, T.D., Acedo, G.L.: Measures of Noncompactness in Metric Fixed Point Theory. Birkhäuser Basel (1997)

36. Wang, J., Ibrahim, A.G., Feckan, M.: Nonlocal impulsive fractional differential inclusions with fractional sectorial operators on Banach spaces. Appl. Math. Comput. 257, 103-118 (2015)

37. Wang, J., Li, X.: Ulam-Hyers stability of fractional Langevin equations. Appl. Math. Comput. 258, 72-83 (2015)

38. Wang, J., Li, X.: A uniformed method to Ulam-Hyers stability for some linear fractional equations. Mediterr. J. Math. 13, 625-635 (2016)

39. Zhou, Y.: Basic Theory of Fractional Differential Equations. World Scientific, Singapore (2014)

40. Zhou, Y., He, J.W., Ahmad, B., Tuan, N.H.: Existence and regularity results of a backward problem for fractional diffusion equations. Math. Methods Appl. Sci. (2019). https://doi.org/10.1002/mma.5781 